\title{
High-Precision Catalysts: Remarkable Regioselective Hydrofomylation of Internal Alkenes by Encapsulated Rhodium Complexes
}

Mark Kuil, Theresa Soltner, Piet W. N. M. van Leeuwen, Joost N. H. Reek*

Van 't Hoff Institute for Molecular Sciences, University of Amsterdam, Nieuwe Achtergracht 166, 1018 WV Amsterdam (The Netherlands)

\section{Experimental details: Catalysis.}

The hydroformylation experiments were carried out in a stainless steel autoclave (volume $150 \mathrm{ml}$ ) charged with an insert suitable for 14 reaction vessels (including Teflon mini stirring bars) for conducting parallel reactions. The appropriate reaction conditions (partial $\mathrm{CO}$ and $\mathrm{H}_{2}$ pressures, reaction temperatures, reaction times and choice of substrate) can be found in Table 1 of the article. The substrates (1-octene, trans-2-octene and trans-3-octene) were filtered freshly over basic alumina to remove possible peroxide impurities. The solvent toluene was distilled from sodium prior to use. The autoclave was charged with $0.35 \mu \mathrm{mol}$ of $\left[\mathrm{Rh}(\mathrm{acac})(\mathrm{CO})_{2}\right], 3.2 \mu \mathrm{mol}$ of phosphine, (if necessary) 9.6 $\mu \mathrm{mol}$ of zinc(II) tetraphenylporphyrin, $0.0017 \mathrm{ml}$ of dipea, $368 \mu \mathrm{mol}$ of substrate and 184 $\mu \mathrm{mol}$ of decane in $0.50 \mathrm{ml}$ of toluene. Before starting the catalytic reactions, the charged autoclave was purged three times with 10 bar of syngas $\left(\mathrm{CO} / \mathrm{H}_{2}=1 / 1\right)$ and then pressurized to the appropriate partial pressures. After catalysis the autoclave was cooled down to $0{ }^{\circ} \mathrm{C}$, the pressure was reduced to 1.0 bar and a few drops of tri-n-butylphosphite were added to all the reaction vessels to prevent any further reaction. The reaction mixtures were NOT filtered over silica/ alumina (to remove catalyst residues), because filtration may cause retention of the aldehyde products and thus influence the GC-result! The reaction mixtures were diluted with dichloromethane for GC-analysis. All reactions were performed in duplo. Further details can be found in the main text of the article. 


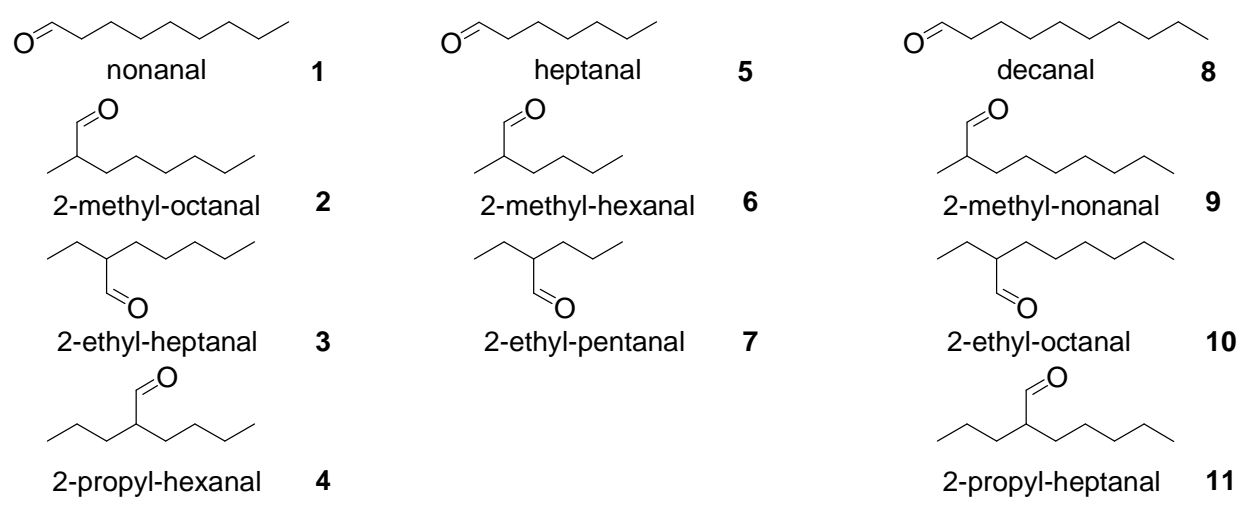

Table S1. Hydroformylation of internal alkenes with both non-encapsulated and encapsulated catalyst assemblies. ${ }^{a}$

\begin{tabular}{|c|c|c|c|c|c|c|c|c|}
\hline entry & olefin & template & conv (\%) & iso $(\%)^{\mathrm{b}}$ & $5(\%)$ & $6(\%)$ & $7(\%)$ & \\
\hline 1 & tr-2-hexene & - & 12 & 0 & 0 & 55.0 & 45.0 & \\
\hline 2 & tr-2-hexene & Zn-tpp & 21 & 0 & 0 & 8.3 & 91.7 & \\
\hline 3 & tr-3-hexene & - & 15 & 0 & 0 & 0 & 100 & \\
\hline 4 & tr-3-hexene & Zn-tpp & 28 & 0 & 0 & 0 & 100 & \\
\hline
\end{tabular}

Table S2. Hydroformylation of internal alkenes with both non-encapsulated and encapsulated catalyst assemblies. ${ }^{a}$

\begin{tabular}{cccccccccc}
\hline entry & olefin & template & $\mathrm{t}(\mathrm{h})$ & conv $(\%)$ & iso $(\%)^{\mathrm{b}}$ & $\mathbf{8}(\%)$ & $\mathbf{9}(\%)$ & $\mathbf{1 0}(\%)$ & $\mathbf{1 1}(\%)$ \\
\hline 1 & tr-2-nonene & - & 66 & 15 & 0.3 & 0 & 54.6 & 45.1 & 0 \\
2 & tr-2-nonene & Zn-tpp & 66 & 29 & 1.2 & 0 & 13.2 & $\mathbf{8 5 . 6}$ & 0 \\
3 & tr-3-nonene & - & 60 & 20 & 0.4 & 0 & 0 & 49.6 & 50.0 \\
4 & tr-3-nonene & Zn-tpp & 60 & 35 & 1.3 & 0 & 0 & 27.1 & $\mathbf{7 1 . 6}$
\end{tabular}

${ }^{\mathrm{a}}\left[\mathrm{Rh}(\mathrm{acac})(\mathrm{CO})_{2}\right]=0.70 \mathrm{mmol} / \mathrm{l}$ in toluene, pressure $=20 \mathrm{bar}\left(\mathrm{CO} / \mathrm{H}_{2}=1 / 1\right)$, temperature $=25{ }^{\circ} \mathrm{C}$, substrate $/ \mathrm{rhodium}=1052$, [phosphorus] $=6.4 \mathrm{mmol} / \mathrm{l}$. ${ }^{\mathrm{b}}$ Iso denotes the total amount of isomerization based on the total product distribution.

Table S3. Hydroformylation of 1-octene with both non-encapsulated and encapsulated catalyst assemblies. ${ }^{a}$

\begin{tabular}{ccccccccc}
\hline entry & template & $\mathrm{PH}_{2}$ (bar) & conv $(\%)$ & iso $(\%)^{\mathrm{b}}$ & $\mathbf{1}(\%)$ & $\mathbf{2}(\%)$ & $\mathbf{3}(\%)$ & $\mathbf{4}(\%)$ \\
\hline 1 & - & 10 & 5.9 & 2.9 & 72.1 & 25.0 & 0 & 0 \\
2 & $\mathrm{Zn}-\mathrm{tpp}$ & 10 & 52 & 1.3 & 35.3 & 63.4 & 0 & 0 \\
3 & - & 15 & 8.9 & 2.8 & 71.6 & 25.6 & 0 & 0 \\
4 & $\mathrm{Zn}-\mathrm{tpp}$ & 15 & 57 & 1.1 & 36.3 & 62.6 & 0 & 0 \\
5 & - & 5 & 6.3 & 2.7 & 72.1 & 25.2 & 0 & 0 \\
6 & $\mathrm{Zn}-\mathrm{tpp}$ & 5 & 54 & 1.1 & 36.6 & 62.3 & 0 & 0 \\
\hline
\end{tabular}

